\title{
REFORMA AGRÁRIA NO ESTADO DO TOCANTINS, EMBASAMENTO HISTÓRICO E ATUAL NA MICRORREGIÃO
}

\author{
Ana Clara S. Rodrigues; Gessica L. de Carvalho; Jakellyne M. da Paz; Leticia N. das Neves*; Paula S. \\ Ribeiro dos Santos5.
}

\author{
Instituto Federal de Educação Ciência e Tecnologia do Tocantins- Campus Araguatins. \\ Cidade : Araguatins. Estado :Tocantins. CEP:77950-000 \\ Autor para correspondência: Leticia N. das Neves. leticianunes.neves@hotmail.com
}

\begin{abstract}
RESUMO: Em 1985-89 a reforma agrária ganhou força na região do bico do papagaio, causando grandes conflitos entre os proprietários de terra e os componentes do movimento MST, esse período ficou conhecido em virtude da quantidade de pessoas que foram mortas e feridas, para que fosse conseguido êxito naquilo que estava sendo reivindicado. Atualmente os movimentos da reforma agrária no estado do Tocantins são menos violentos, se tornaram mais organizados e articulados, permitindo assim que os objetivos idealizados por este grupo sejam alcançados sem que ocorra tanta violência. 0 artigo trata-se dos resultados de uma pesquisa realizada com base em revisão bibliográfica, e uma visita a campo, em um acampamento de integrantes do movimento MST (Movimento dos Trabalhadores Rurais Sem Terra), que estava localizado as margens da rodovia que dá acesso à cidade de Macaúba do Tocantins. $O$ principal objetivo é constatar e apresentar à similaridade e as diferenças entre o movimento que estão ocorrendo atualmente com o que ocorreu nos anos 80 e o que está ocorrendo atualmente. As similaridades encontradas foram a ajuda mútua, o envolvimento dos líderes com a religião, as regras do acampamento em relação a proibição de violência e uso de drogas, a principal diferença encontrada foi só dos meios tecnológicos para escolher a área onde o acampamento deveria ser montado.
\end{abstract}

PALAVRAS-CHAVE: Desenvolvimento rural, Distribuição de terra, justiça social, MST, reforma agrária

\section{AGRARIAN REFORM IN THE STATE OF TOCANTINS, HISTORICAL AND CURRENT EMBASSMENT IN MICRORREGION}

\begin{abstract}
In 1985-89 agrarian reform gained strength in the Bico de Papagaio region, causing major conflicts between landowners and components of the MST movement, this period was known because of the number of people who were killed and wounded, to be achieved in what was being claimed. Nowadays the agrarian reform movements in the state of Tocantins are less violent, more organized and articulated, thus allowing the goals idealized by this group to be achieved without much violence. The article deals with the results of a research carried out based on a bibliographical review, and a field visit, in a camp of members of the MST movement (Movimento dos Trabalhadores Rurais Sem Terra), which was located on the banks of the highway that gives access to the city of Macaúba do Tocantins. The main objective is to verify and present the similarity and differences between the movement that is currently occurring with what occurred in the 1980s and what is currently occurring. The similarities found were mutual help, the involvement of leaders with religion, the rules of the camp regarding the prohibition of violence and drug use, the main difference found was only the technological means to choose the area where the camp should be mounted.
\end{abstract}

KEYWORDS: Rural development, Land distribution, social justice, MST, agrarian reform

\section{INTRODUÇÃO}

A reforma agrária é um conjunto de medidas para promover a melhor distribuição da terra mediante modificações no regime de posse e uso, a fim de atender aos princípios de justiça social, desenvolvimento rural sustentável e aumento de produção. Os conflitos agrários no Tocantins tiveram início quando este ainda se encontrava ligado ao estado de Goiás, essa 
região era até então conhecida por extremo norte de Goiás. Tudo começou com a chegada dos imigrantes que vinham de vários estados brasileiros, que se deslocavam com o intuito de melhorar a sua situação de vida, pois sabiam que iriam encontrar solos férteis que iriam proporcionar a produção agrícola e pecuária, essas terras não possuíam documentação, então legalmente não possuía proprietários (Soares, 2009).

Em meados dos anos 60 começaram a chegar ao estado grileiros e fazendeiros. Os fazendeiros possuíam documentos de terras cedidos pelo estado, entretanto essa documentação não era considerada legal, pois os documentos apresentados se tratavam apenas de registros paroquiais. Os anos se passaram e a quantidade de imigrantes foi aumentando, por consequência a disputa por terras também, a falta de documentações legais das terras só agravou a situação o que cominou nos primeiros conflitos agrários (Maria, 2013).

Nos anos 80, o movimento da reforma agrária intensificou-se no norte do Tocantins, uma das cidades que apresentou destaque nesse fenômeno social foi a cidade de Buriti do Tocantins, que se tornou nacionalmente conhecida na época por conta dos conflitos violentos travados entre os grileiros, os posseiros e os integrantes do movimento MST (Movimento dos Trabalhadores Rurais Sem Terra). 0 principal objetivo do movimento naquela época era acabar com os latifúndios, através da divisão e distribuição de terra para aqueles que pretendiam usá-las como moradia e para produzir, alimentos que seriam usados tanto para a sua subsistência como para a venda no comercio local.

Os conflitos se agravaram, quando os fazendeiros começaram a expulsar os posseiros de suas terras, isso era feito com o apoio de documentos falsificados por meio da grilagem. Por conta das plantações, os posseiros resistiam em sair das suas terras, com isso, por terem um maior poder aquisitivo os fazendeiros contratavam pistoleiros, para matar aqueles que oferecessem resistência em sair da propriedade, as mortes eram censuradas assim a imprensa não poderia divulgar a barbaridade dos crimes que estavam sendo cometidos. Como estratégia de resistência os posseiros e camponeses passaram a ajudar-se de forma mútua.

Entre os integrantes deste movimento, encontravam-se famílias sem estrutura e moradia, sendo boa parte oriundas das regiões norte e nordeste do país, e este movimento tinha como intermediadores e organizadores, os coordenadores da pastoral da terra, destacando-se o que teve maior influência no movimento que foi o padre Josimo, o qual sofreu um atentado em 15 de abril de 1986 quando 5 tiros foram disparados contra a sua Toyota (Silva, 2011)1, e acabou sendo assassinado no dia 10 de maio de 1986 covardemente enquanto subia as escadarias do prédio Mitra Diossetica de imperatriz, onde funcionava o escritório da CPT (Comissão Pastoral da Terra), em Araguaia-Tocantins.

Josimo Morais Tavares nasceu em 1953 na cidade de Marabá no estado do Pará, e faleceu em 10 de maio de 1986 na cidade de imperatriz maranhão. Foi um sacerdote católico brasileiro, coordenador da Comissão Pastoral da Terra e foi assassinado a mando de fazendeiros do Bico do Papagaio (atual estado de Tocantins (Silva, 2011), por sua defesa aos trabalhadores rurais. Durante sua trajetória ele defendeu diversas famílias que lutavam por uma posse de terra, durante 0 conflito houve muitas mortes e pessoas feridas a qual se encontravam envolvidas no movimento, o padre Josimo além de defender as famílias que se encontravam desabrigadas, ele lutava pela causa junto a elas, era visto pelos fazendeiros como inimigo, porém mesmo com ameaças vindas por parte dos proprietários das terras ele não se intimidava em defender tal causa.

Seu legado de luta e defesa dos trabalhadores rurais permaneceu como um exemplo a ser seguido, muitas características da organização do movimento que ele liderava se faz presente até hoje nos acampamentos MST. Araguatins é uma cidade que faz parte do Tocantins e possui dois acampamentos do movimento sem-terra em seus arredores, ambos com características bem parecidas com as do padre Josimo, um deles se encontra próximo ao distrito de Mata Velha, e o outro onde foi realizada a pesquisa se encontra próximo a cidade de Macaúba do Tocantins.

\section{MATERIAL E MÉTODOS}

Para elaboração do trabalho, foi realizada uma pesquisa bibliográfica que embasou o conhecimento histórico sobre a temática, e também foi realizada pesquisa de campo no acampamento do FNL (Frente Nacional de Luta Campo e Cidade), localizado 
próximo ao município de Araguatins, onde foi aplicado questionário com 10 (dez) perguntas diretas, para 12 (doze) integrantes do acampamento, entre eles o representante do acampamento que faz parte da Confederação Nacional da Agricultura Familiar no Brasil, além dos coordenadores internos do movimento. Dentre as perguntas propostas, questionou-se a respeito do grau de escolaridade, funcionamento interno do acampamento, participação de cada entrevistado no movimento, bem como, os motivos que os levaram a fazer parte do movimento na região.

Figura 1. Acampamento as margens da rodovia transamazônica, próximo a cidade de Araguatins

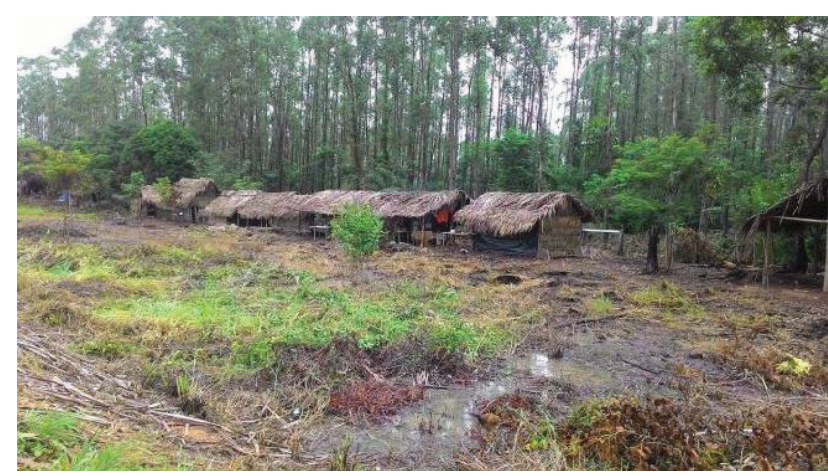

Figura 2. Bandeira do acampamento visitado para elaboração do trabalho (acampamento comandante Fidel)

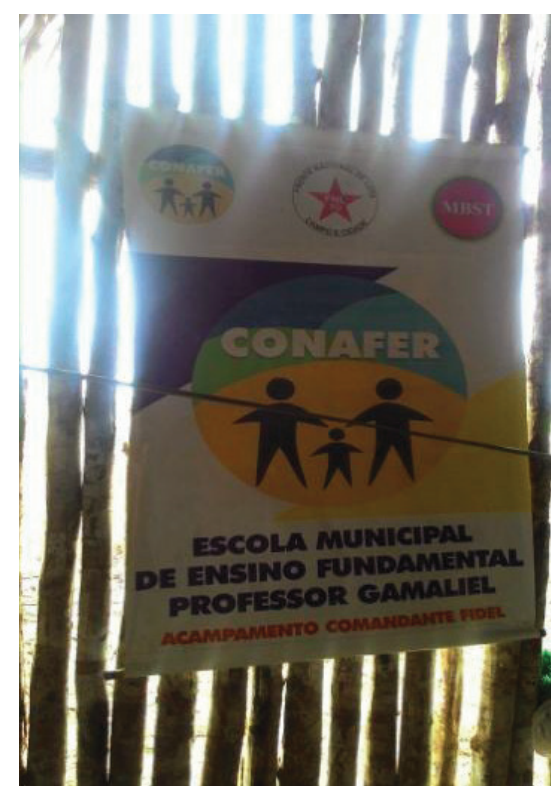

\section{RESULTADOS E DISCUSSÃO}

Diante das discussões, observações no local e respostas obtidas, foi possível compreender qual tipo de organização que se encontrava no local, que é bastante similar ao do acampamento do padre Josimo, pois ambos apresentam ajuda mútua para conseguir alimento e para manter a segurança dos integrantes, além de seguir regras dentro do acampamento, como a proibição do uso de drogas ilícitas, violência com mulheres e crianças, roubo dentro e fora do acampamento. Além de uma característica comum entre os líderes, é que ambos estão ligados diretamente a religião, pois o representante do acampamento visitado é consagrado pastor, enquanto Josimo Morais era padre, e ambos são natural do estado do Pará, e não medem esforços para defender as pessoas que fazem parte do grupo.

Dentre as diferenças encontradas entre os acampamentos foram o modo de escolha do local para apropriação dos integrantes, pois na década de 80 o local era escolhido através do tamanho dos latifúndios e pela riqueza e fertilidade do solo para então a formação do acampamento próximo ao local, e posteriormente a compra da terra através do INCRA (Instituto Nacional de Colonização e Reforma Agrária), que iria desapropriar as terras e realizar a divisão e distribuição dos assentamentos.

No contexto atual, a terra para apropriação é buscada através de pesquisas realizadas pelo georeferencial da área, para saber se a mesma é pública ou privada, se apresenta processos administrativos decorrentes de trabalho escravo ou infantil, se foi adquirida através de desvio de verba pública, ou se houve desmatamento ilegal na área, o que facilita a posse da terra evitando assim conflitos violentos. Outra diferença encontrada é a questão dos conflitos agrários, onde no acampamento do padre Josimo situado no município do Buriti, sofreu diversos atentados e repressões, entre eles a queima de 60 casas no acampamento, várias mortes de fazendeiros e dos componentes do movimento, e assassinato do líder, já no acampamento atual no momento não houve registro de nenhuma morte.

Conclui-se que o movimento sem-terra mesmo com o passar dos anos, continua sendo necessário para que ocorra a distribuição das terras de forma igualitária, pois as políticas públicas só se tornam válidas quando, aqueles que têm interesse lutam e reivindicam pelos seus direitos. No atual momento, o número de casos de violência no campo relacionado com esse tipo de movimento social é bem menor, quando comparado 
com os primeiros movimentos; percebe-se que, atualmente o grupo é mais organizado, possui a tecnologia e os meios de comunicação ao seu favor, tornando-se assim, de certa forma, mais fácil conseguir alcançar seus objetivos.

Os anos se passaram, mais as dificuldades vividas por aqueles que fazem parte desse movimento social continuam praticamente as mesmas, as famílias possuem dificuldade em conseguir alimento, água e manter as crianças nas escolas. Para que esse quadro mude, é necessário que o governo viabilize políticas de ações socioeducacionais mais efetivas, que consigam de fato, viabilizar a oferta de programas de saúde, educação, infraestrutura e vida mais digna para esse grupo social batalhador.

\section{AGRADECIMENTOS}

Primeiramente agradecemos a Deus que nos permitiu que este momento fosse vivido por nós, trazendo alegria e conhecimento e a todos que contribuíram para a realização deste trabalho.

Agradecemos aos nossos pais, pelo amor, carinho, paciência e seus ensinamentos.

Ao Instituto Federal de Educação Ciência e Tecnologia do Tocantins- Campus Araguatins, pelo excelente ambiente oferecido aos seus alunos e os profissionais qualificados que se disponibilizam para nos ensinar.

Agradecemos a professora Quitéria Alcântara por toda orientação e ajuda que nos foram dadas

\section{REFERÊNCIAS BIBLIOGRÁFICAS}

OLIVEIRA, N. et.al. conflito e luta pela posse de terra na região do bico do papagaio: TO. Congresso da sociedade brasileira de economia, administração e sociologia rural.

Disponivel em: <http://www.academia.edu/7870332/ CONFLITOS_E_LUTA_PELA_POSSE_DA_TERRA_ NA_REGI\%C3\%830_DO_BICO_DO_PAPAGAIO_ TOCANTINS> acesso em 12 de fevereiro de 2017.

SILVA, M.P. Padre Josimo Moraes Tavares e a atuação da Comissão Pastoral da Terra (CPT) nos conflitos agrários da Araguaia-Tocantins (1970 - 1986). 175 f. Dissertação (Mestrado em História), Universidade Federal de Goiás, Goiânia, 2011.

SOARES, M.S.S. Ecos e silenciamentos na luta do padre Josimo aos movimentos sociais na região do bico do papagaio-to na década de 1980.universidae federal da paraíba centro de educação. Programa de Pós-graduação Mestrado em Educação. João pessoa, 2013.

SOARES, Z.A.B. Agricultura familiar, movimentos sociais e desenvolvimento rural na região do Bico do PapagaioTocantins: um estudo sobre as relações entre sociedade civil e desenvolvimento. 250 f. (Mestrado em Desenvolvimento Sociedade e Agricultura), Universidade Federal Rural do Rio de Janeiro. Seropédica, 2009. 